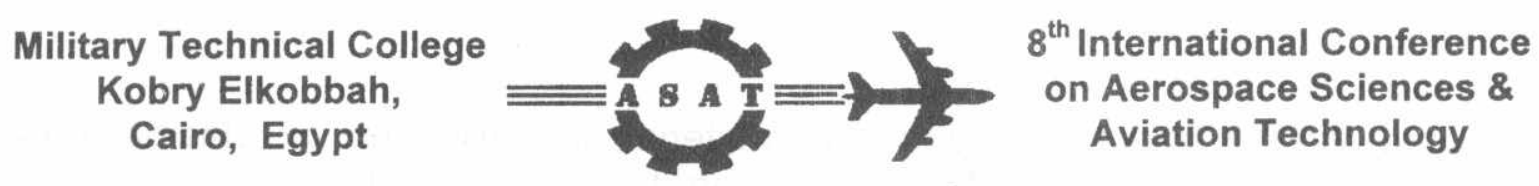

\title{
CHARACTERIZATION OF DIFFERENT HOT PRESSED AL- COMPOSITE ARCHITECTURES.
}

\author{
B. M. RABEEH*, M. M. MOUSSA ${ }^{+}$, H. M. ELTAHER ${ }^{+}$AND A. EL-SOAALY
}

\begin{abstract}
:
There is a continually driving desire to enhance the performance of commercial and military aircrafts in aerospace industries. For the development of improved high performance structural materials, Hot Isostatic Pressing (HIP), (the simultaneous application of heat and high-pressure) has become a standard production process in many industries. Metal matrix composite can have properties that differ from those of conventional metals and alloys. However, in order to obtain such properties a precise control of the composite processing techniques is required. Different aluminum metal matrix composite architectures are almost exclusively produced by hot Isostatic pressing techniques. A comparison with the conventional monolithic matrix that produced by the same technique is obtained using scanning electron microscope imaging and mechanical testing considering the effect of fiber diameter and volume fraction. Based on the mechanical testing and a microscopic examination, the optimum processing parameters and techniques were obtained.
\end{abstract}

\section{INTRODUCTION:}

Hot Isostatic Pressing (HIP), has become a standard production process in many industries. The temperature, pressure and process time are all controlled to achieve the optimum material properties. The Economics of HIPping offer many advantages as following; (1) reduces scrap and improves yield, (2) frequently allows replacement of wrought components by castings, (3) can reduce quality assurance requirements by improving material properties and reducing property scatter, (4) Often, the savings on radiographic costs will cover the costs of HIP, and finally, HIP maximizes material utilization by improving material properties. Besides, HIP parameters can be established to minimize subsequent heat treatment requirements [1-5]. HIP is widely used in the casting industry to remove the internal porosity generated during the casting process. This results in improved strength, ductility and fatigue life of the casting. The rejection rate is reduced and the mechanical properties of the parts are more consistent. Casting alloys that are routinely HIPped include nickel, cobalt, aluminum and titanium[6].

Powder Metallurgy also utilizes HIPping as it consolidates fine powders into components approaching $100 \%$ theoretical density. Pre-sintered components are fully densified or powders are encapsulated in a sealed container, then HIPped directly into a near-net shape. The process lends itself to the processing of tool steels, cemented tungsten carbide, copper, nickel and cobalt alloys. Ceramics and composite materials can also be formed in this manner[5-8].

\footnotetext{
* Department of Materials Science and Engineering, MTC, Cairo.

+ Department of Automotive Engineering, MTC, Cairo.

+ Department of Mechanical Engineering, MTC, Cairo.
} 
HIP is used for the bonding of dissimilar material, consolidation of plasma coatings, improvement of welds, processing soft and hard magnetic material and a variety of ceramic applications. In applications such as turbine engine rebuilding, HIP removes the effects of fatigue in components, which have reached the end of their service life. The components can be rejuvenated for further service [9-12].

In this work, HIPping process is established on rolled aluminum-foils with steel fibers to form ccmposites. Different composite architectures are produced in this technicjue as foilfiber-foil HIPed at high temperature $\left(640^{\circ} \mathrm{C}\right)$ for one-hour holding time that established from previous work. Al-MMCs produced in a uni-direction $\left[0^{\circ}\right]$, cross ply $\left[0 / 90^{\circ}\right]_{2} \mathrm{~S}$, and woven-fibers. Monolithic matrix of aluminum is also produced by the same technique rolled foil in five plies.

Scanning electron microscopy with EDAX were established to set the homogeneity of interface and diffusion processing between solid solution of aluminum and steel through fiber, interface and matrix. The control and adjusting of diffusion processing is a main goal of obtaining bonded as well as thin uniform interface. Mechanical testing achieved using instron servo-hydraulic test unit with 10 ton loading. A comparison between different Al-MMC;s architecture and monolithic matrix was obtained. Effects of fiber diameter as well as and effect of fiber volume fraction was achieved for uni-direction type composites.

\section{EXPERIMENTAL WORK:}

A servo-hydraulic test unit with 10-ton loading was used for tensile testing of different ALsamples prepared by HIPing. Four sets of samples prepared from uni-direction ALcomposites with fiber diameter $150 \mu \mathrm{m}$ (volume fraction $=0.05$ and 0.15 ) and $300 \mu \mathrm{m}$ (volume fraction $=0.15$ and 0.3 ). Another sets of samples were prepared from $[0 / 90]_{2 S}$ with fiber diameter $150 \mu \mathrm{m}$, woven fiber with fiber diameter $150 \mu \mathrm{m}$ and monolithic $\mathrm{AL}$ matrix.

Several types of aluminum based MMCs have been developed for applications in aerospace. The main reasons for adding reinforcements to are to increase the strength, stiffness or wear resistance but this is usually achieved at the expense of other properties such as ductility. The reinforcements be in the form of continuous fibers (e.g. steel fibers), at different composite architectures in a uni-direction $\left[0^{\circ}\right]$, cross ply $\left[0 / 90^{\circ}\right]_{2 S}$, and wovenfibers. Monolithic matrix of aluminum is also produced by the same technique rolled foil in five plies.

The choice of steel fibers as the reinforcement in aluminum composites is primarily due to its excellent combination of physical properties, availability and cost. The following are some important properties of the Al/steel fiber composite. The composite can be used in aerospace systems replacing certain components because of its structural performance

MMCs present some unique challenges for designers and materials engirieers in the aerospace industry. From the materials stand point, they require an understariding of the interaction of two chemically different materials under extreme processing and operating conditions. From the design stand point, they require reconsideration in terms of component design, fabrication, lifing and quality assurance in order to obtain the most benefits from these materials[1],[9]. 


\section{RESULTS AND DISCUSSIONS}

\section{1- MICROSTRUCTURAL ANALYSIS}

Scanning Electron Microscopy images were obtained for finally polished and etched AlMonolithic matrix Figure 1a. The image reveals clear bonding without delamination of five plies of Al-foils HIPed at $640^{\circ} \mathrm{C}$ for one hour holding time. Besides Al-MMCs samples at different composite architectures in a uni-direction $\left[0^{\circ}\right]$, cross ply $\left[0 / 90^{\circ}\right]_{2 s}$, and wovenfibers were obtained. The effect of temperature, and holding time was also investigated to be $640^{\circ} \mathrm{C}$ for one hour to all samples. Figure $1 \mathrm{~b}$ reveals a clear image of fiber-matrixinterface as example for successive bonding verification. A quantitative analysis with EDAX to test diffusion analysis (Figure 1c) at fiber-matrix interface revealed interface with nearly $50 \% \mathrm{Al}$ and $50 \%$ steel was obtained.

A clear thin continuous and uniform interface that established at $640^{\circ} \mathrm{C}$ for one hour (Fig. 1b) correlated with strong bonding of $50 \% \mathrm{Al}$ and $50 \%$ steel. (Figure 1c) and other different diffusion zones uniformly obtained across fiber (Fig. 1b). Strong evidence of selfmechanical behavior of both fiber and matrix should be obtained in different composite architectures next section.

\section{2- MECHANICAL BEHAVIOR}

Mechanical behavior and fracture surface analyses were established for all the sets of samples HIPed at the same testing temperatures mentioned before. Another sample of monolithic aluminum matrix was HIPed and prepared using same technique for comparison. A comparison between monolithic aluminum matrix (Fig. 2a) and different Al-composite architectures with; uni-direction fiber at diameter of $300 \mu \mathrm{m}$ (Figure 2b), cross-ply of [0/90] at fiber diameter of $150 \mu \mathrm{m}$ (Figure 2c) and woven fiber at fiber diameter of $150 \mu \mathrm{m}$ (Figure 2c)

Effects of fiber diameter and volume fraction were achieved at Figures $1 a, b$ for AI-MMC [0] with steel fiber of $150 \mu \mathrm{m}$ and volume fraction of $0.05 \%$ and $0.15 \%$ respectively. Increasing fiber diameter to $300 \mu \mathrm{m}$ (Figure 3c,d) reveals the increased strength at different volume fraction of $0.15 \%$ and $0.3 \%$.

Finely effects of Al composite architectures, fiber diameter as well and fiber volume fraction was gathered in Table 1 . Besides, a clear correlation between the ultimate tensile stress as well and yield stress compared to fiber volume fraction at different fiber diameters was established at Figure 4

Fracture surface (Figure 5a-d) of finally established Al-samples at $640^{\circ} \mathrm{C}$ at one hour for monolithic Al-matrix, uni-direction, cross-plies, and woven fibers respectively were obtained. Ductile-dimpled fracture surface was the matrix criteria, with fiber pull our behavior. 


\section{CONCLUSIONS}

Aluminum-metal matrix composites are an important development of the last few decades. Nowadays aluminum reinforced with steel fibers form the most widely irivestigated matrices for use in MMCs. This popularity as a matrix material can be attributed to its low cost relative to other light structural metals (like magnesium and titanium). Besides, its current dominance on the aerospace structural application market, its introduction and acceptance in the automotive engine market and its overall versatility in terms of properties and ease of fabrication. These factors make property enhancement by reinforcement an attractive proposition.

MMCs present some unique challenges for designers and materials engineers in the aerospace industry. From the materials stand point, they require an understanding of the interaction of two chemically different materials under extreme processing and operating conditions. These parameters were established at $640^{\circ} \mathrm{C}$ for one hour holding time. From the design stand point, they require reconsideration in terms of component design, fabrication and quality assurance in order to obtain the most benefits from these materials.

Design of different AI-MMC architectures was established leading to verification of composite strength however, toughness and ductility were not included in this paper. HIPing parameters were established for both monolithic matrix and different AI-MMC architectures.

\section{References:}

1-T.S.Srivatsan, I.A.Ibrahim, F.A.Mohammed and E.J.Lavernia, "Processing techniques for particulate-reinforced metal matrix composites", J. Materials Science, v:26, p:59655978, 1991.

2- D.Charles, "Addressing the challenge of aircraft component design and manufacture from MMCs", J. Aerospace Engg.(Proc. IMechE), p:1-13, 1992.

3- D.A.McCoy and D.J.Lloyd, Fabrication of graphite fiber reinforced aluminum", Canadian Aeronautics and Space J., v:33, p:11-17, March-1987.

4- A.N.Falazotta, Robert Ruh and George Watt, "Introduction to metal matrix composites in aerospace applications", J. Aerospace Engg., v:1, p:3-17, January-1988.

5- Alan.L.Geiger and Michael Jackson, "Low-expansion MMCs boost avionics", Advanced Materials and Processes", p:23-30, July-1989.

6- Richard DeMeis, "New life for aluminum", Aerospace America, p:26-29, March-1989.

7- P.K.Liaw,R.E.Shannon, W.G.Clark, W.C.Harrigan,H.Jeong and D.K.Hsu, "Determining material properties of metal -matrix composites by NDE", JOM, p:36-40, October-1992.

8- J.Wadsworth and F.H.Froes, "Developments in metallic materials for aerospace applications", JOM, p:12-19, May-1989.

9- J.Doychak, "Metal and intermetallic -matrix composites for aerospace propulsion and power systems", JOM, p:46-51, June-1992.

10- F.H.Froes, "Synthesis of metallic materials for demanding aerospace applications using powder metallurgy techniques"

11- Alan S. Brown, "Rivals take different paths to JSF", Engineering Notes, Aerospace America, August 1998.

12- W.Wei, "High Temperature MMCs for Aero-engines:Challenges and Potentials", Metals and Materials J.,p:430-435, August-1992. 


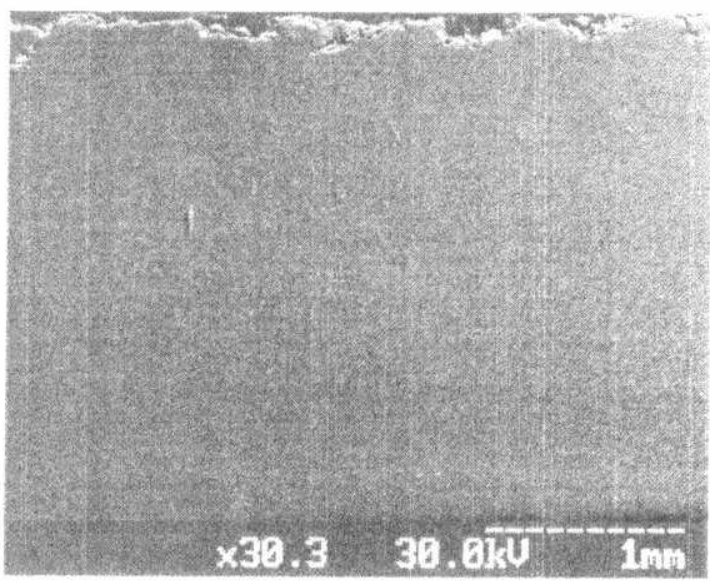

(a)

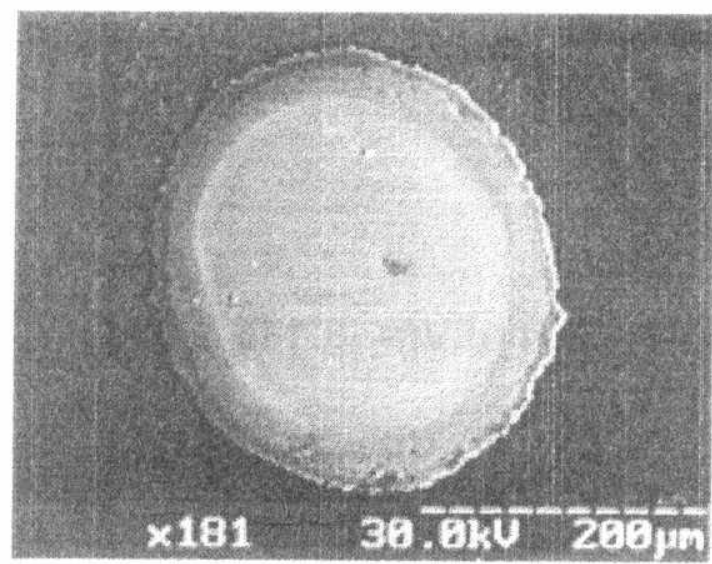

(b)

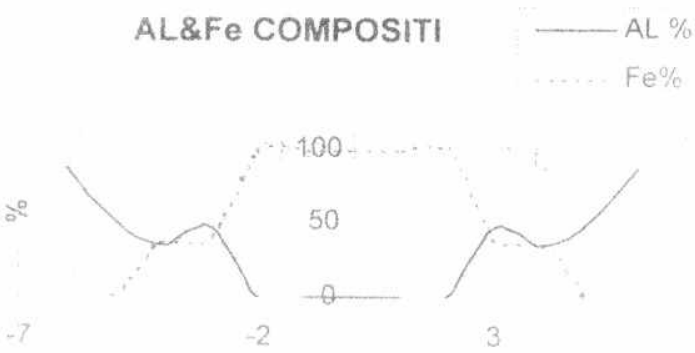

(c)

Figure 1: Scanning Electron Microscopy of (a) Hot Pressed Monolithic Al-matrix,(b) Hot Pressed Al-MMC Reinforced With Steel Fiber, and Diffusion Analysis During HIPing Along Fiber-Interface-Matrix (Fig.1b) 
stress-strain pure laminate.

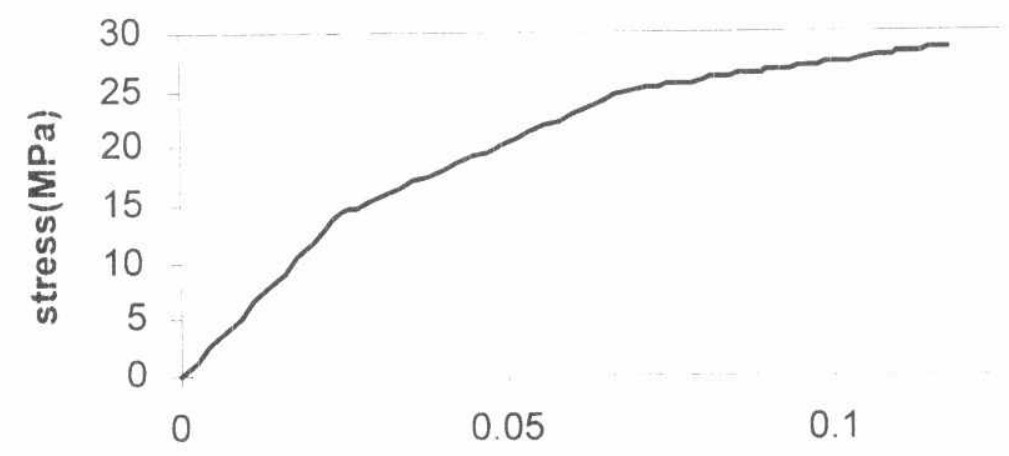

0.15

(a)

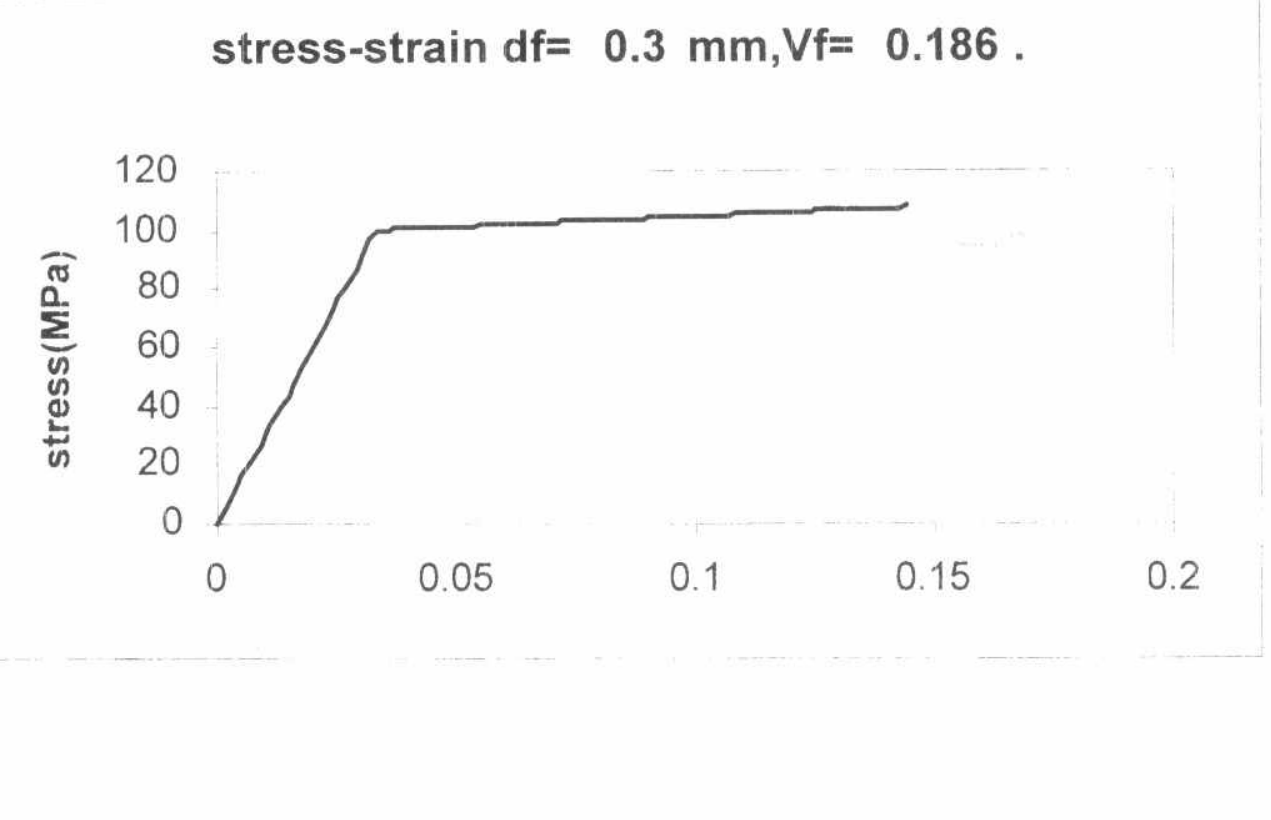

Figure 2a,b: Stress-Strain Diagram of (a) Hot Pressed Monolithic Al-matrix, (b) Hot Pressed [0] AI-MMC Reinforced With Steel Fiber (300 $\mu \mathrm{m})$. 


\section{stress-strain $\mathrm{df}=0.15$ \\ $\mathrm{mm}, \mathrm{Vf}=0.138$.}

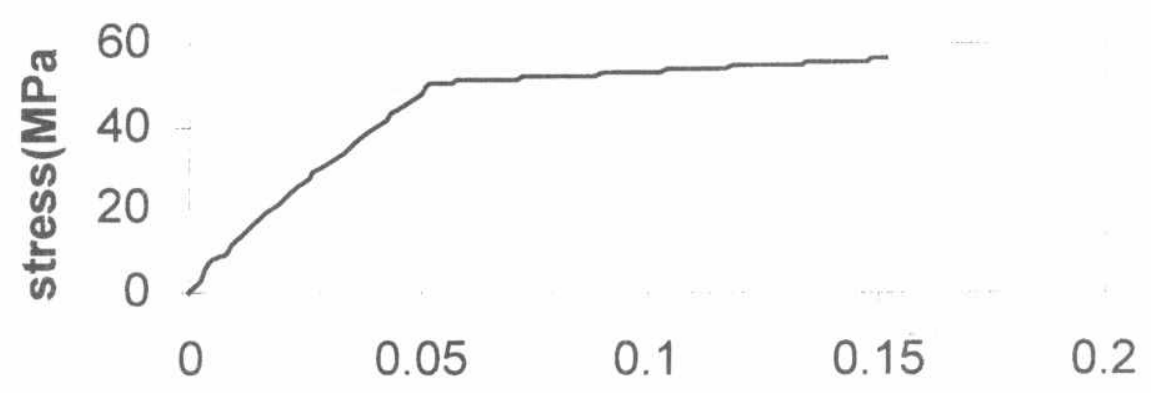

(c)

stress-strain woven composite.

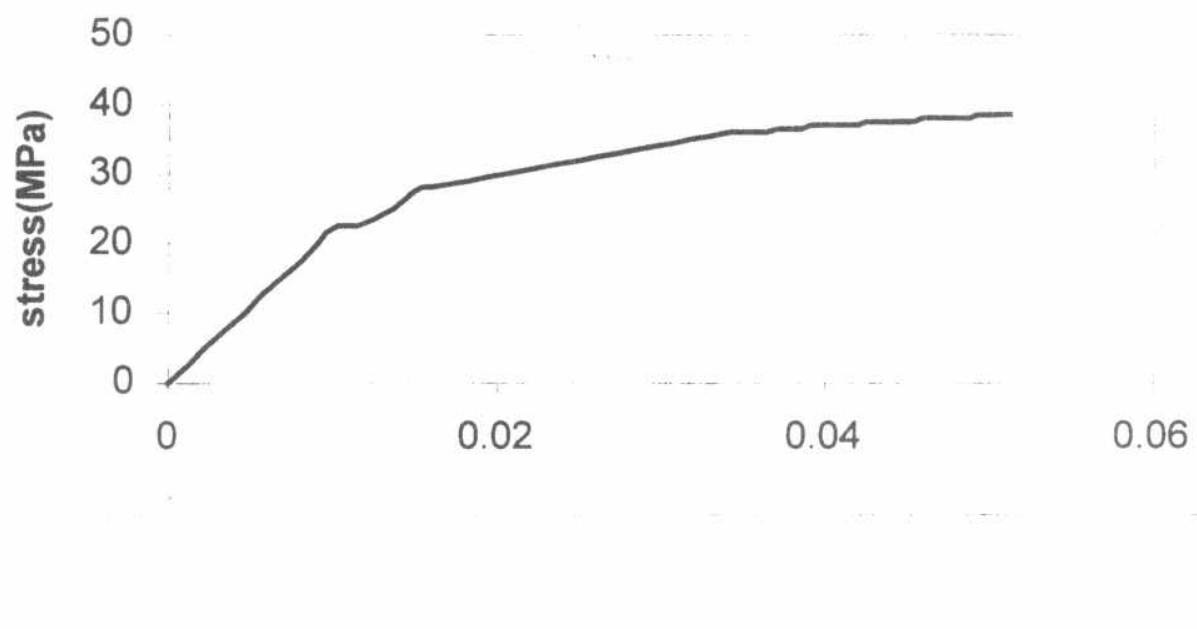

Figure 2c,d: Stress-Strain Diagram of (c) Hot Pressed [0/90] 25 Al-MMG Reinforced With Steel Fiber $(150 \mu \mathrm{m}$ (d) Hot Pressed [0] Al-MMC Reinforced With Woven Steel Fiber $(150 \mu \mathrm{m})$. 


\section{stress-strain $\mathrm{df}=\quad 0.15$ \\ $\mathrm{mm}, \mathrm{Vf}=0.0491$.}

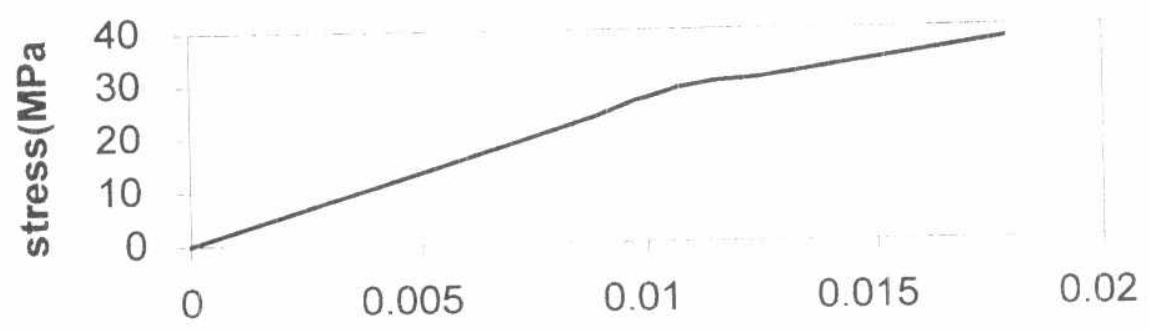

(a)
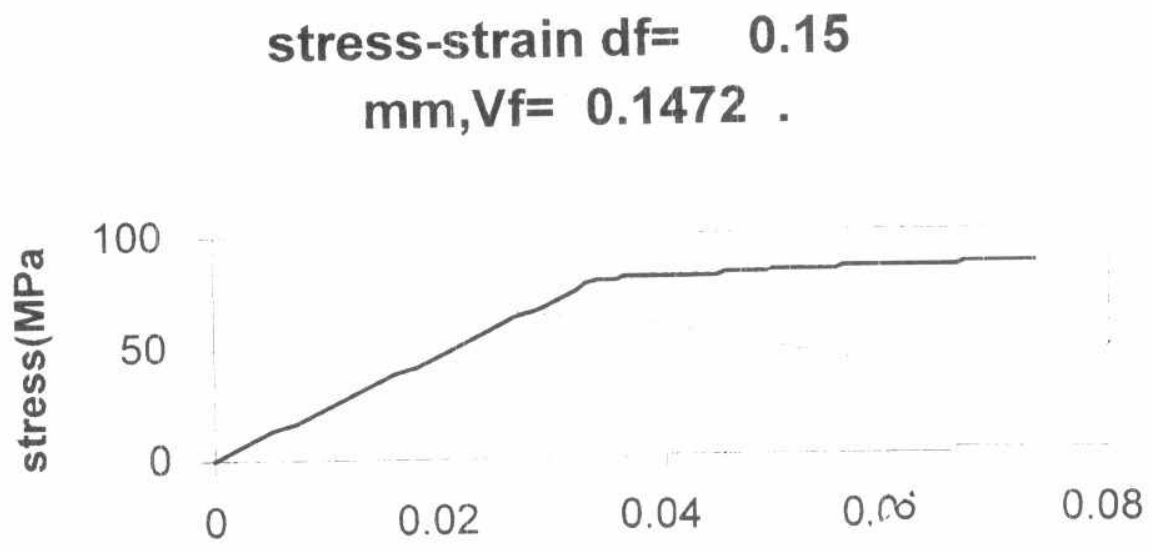

(b)

gure 3a,b: Stress-Strain Diagram of [0] Al-MMC Reinforced With Steel Fiber (150 $\mu \mathrm{m})$ and at Different Volume Fractions (a) Volume Fraction Equal to $0.05 \%$ and (b) Volume Fraction Equal to $0.15 \%$. 


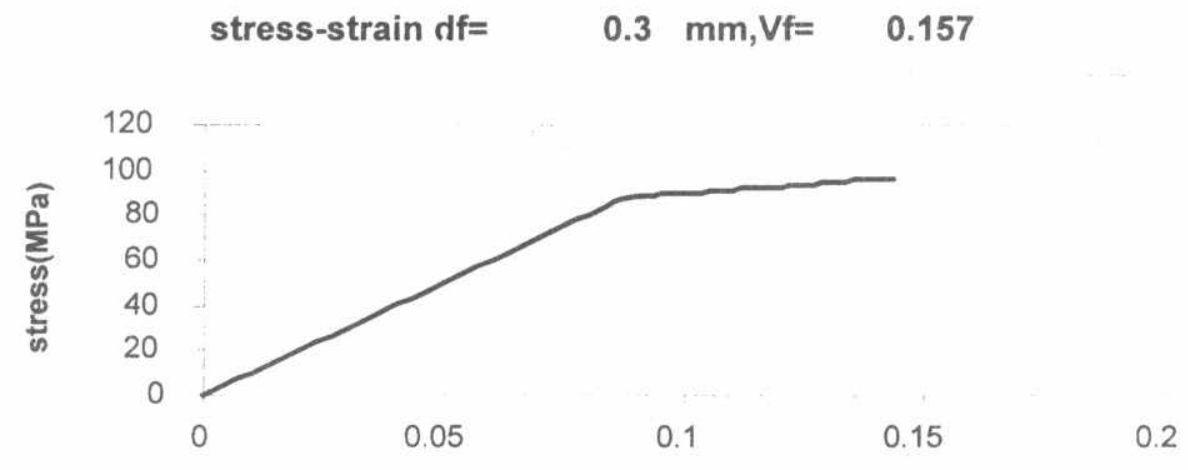

(c)

\section{stress-strain $\mathrm{df}=. \quad 3 \mathrm{~mm}, \mathrm{Vf}=0.294$}

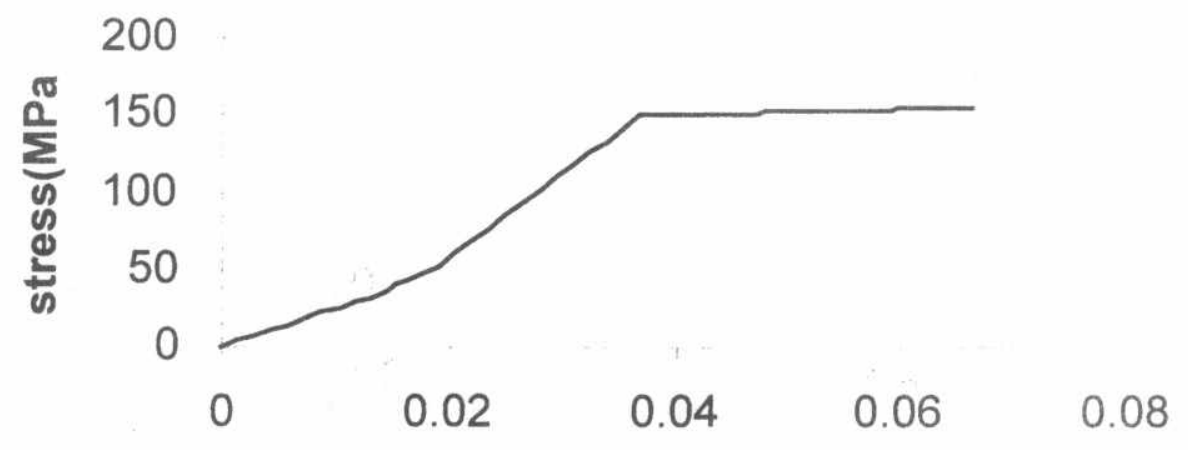

(d)

Figure 3c,d: Stress-Strain Diagram of [0] Al-MMC Reinforced With Steel Fiber $(300 \mu \mathrm{m})$ and at Different Volume Fractions $\quad$ (c) Volume Fraction Equal to $0.16 \%$ and (d) Volume Fraction Equal to $0.3 \%$. 
Table 1: Effects of different AI-MMC architectures, fiber diameter and volume fraction on Composite mechanical properties:

\begin{tabular}{|c|c|c|c|c|c|}
\hline TYPE & $\mathrm{Vf}$ & $\sigma \mathrm{y}$ & $\varepsilon \mathrm{y}$ & $\sigma \mathrm{u}$ & $\varepsilon \mathrm{u}$ \\
\hline $\begin{array}{l}\text { 15 mm } \\
\text { unidirectional. }\end{array}$ & 0.0491 & 28.567 & 0.0107 & 37.456 & 0.0179 \\
\cline { 2 - 6 } & 0.1227 & 72.222 & 0.0217 & 75 & 0.0567 \\
\cline { 2 - 6 } & 0.1472 & 79.418 & 0.034 & 85.35 & 0.0732 \\
\hline \multirow{3}{*}{$\begin{array}{c}0.3 \mathrm{~mm} \\
\text { unidirec:tional. }\end{array}$} & 0.157 & 87.5 & 0.0867 & 96.5 & 0.1433 \\
\cline { 2 - 6 } & 0.186 & 100.148 & 0.0356 & 107.407 & 0.144 \\
\cline { 2 - 6 } & 0.206 & 121.802 & 0.0388 & 121.875 & 0.0836 \\
\cline { 2 - 6 } & 0.294 & 149.444 & 0.0368 & 155.278 & 0.0662 \\
\hline \multirow{3}{*15}{$\mathrm{mm}$ crossply } & 0.0711 & 31.58 & 0.02 & 36.84 & 0.034 \\
\cline { 2 - 6 } & 0.0917 & 44.556 & 0.042 & 48.556 & 0.152 \\
\cline { 2 - 6 } & 0.105 & 46 & 0.078 & 49.6 & 0.118 \\
\cline { 2 - 6 } & 0.138 & 50 & 0.0524 & 56.25 & 0.152 \\
\hline woven & 0.087656 & 22.5 & 0.0114 & 38.57 & 0.0511 \\
\hline pure & 0 & 25.16 & 0.0711 & 28.57 & 0.118 \\
\hline
\end{tabular}

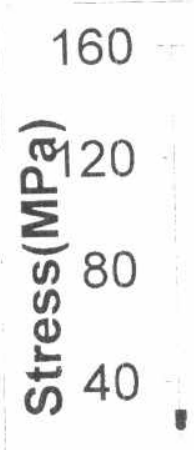

0
0
0.05
0.1
0.15
0.2
0.25
0.3
0.35

\section{Fiber volme fraction (Vf}

$-0.150 \mathrm{~mm} \cup D$ (yield stree)

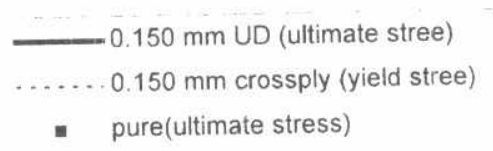

.... $0.3 \mathrm{~mm}$ UD (yield stree)

- $0.3 \mathrm{~mm}$ UD (ultimate stree)

- pure(ultimate stress) $0.150 \mathrm{~mm}$ crossply (utimate stre!e)

- $\quad$ pure(yild stress)

- wo'ven(ultimate stress)

Figure 4: Stress-Fiber volume fraction Diagram of [0] Al-MMC Reinforced With Steel Fiber $(150,300 \mu \mathrm{m})$, [0/90] Al-MMC Reinforced With Steel Fiber $(150 \mu \mathrm{m})$, woven fibers composite and monolithic matrix of Aluminum. 


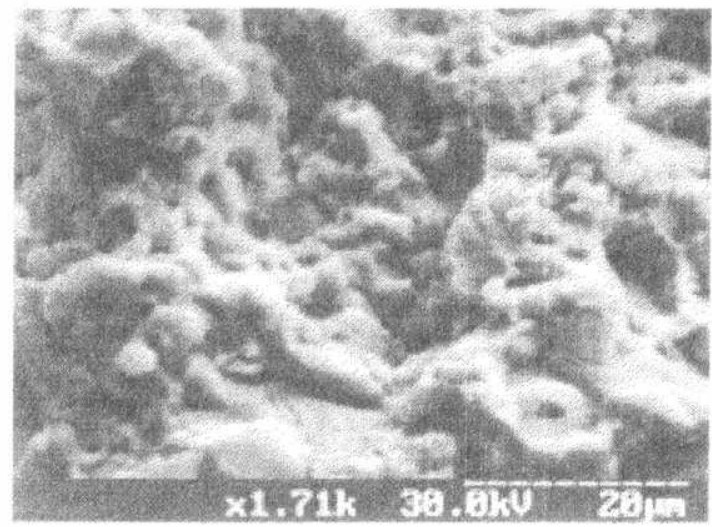

(a)

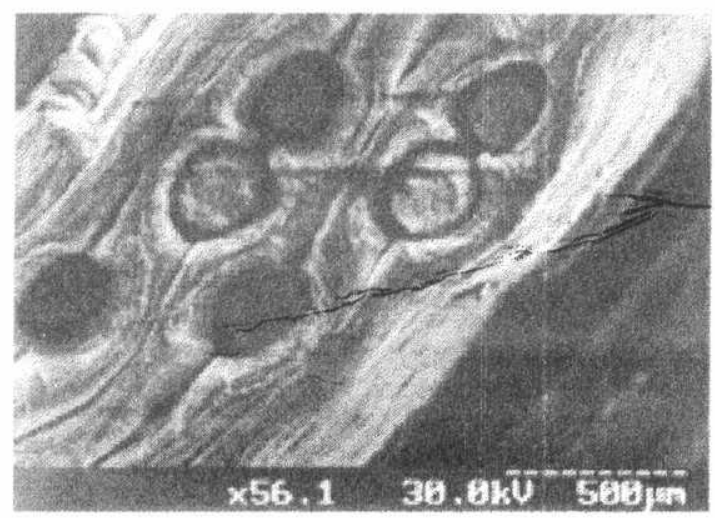

(b)

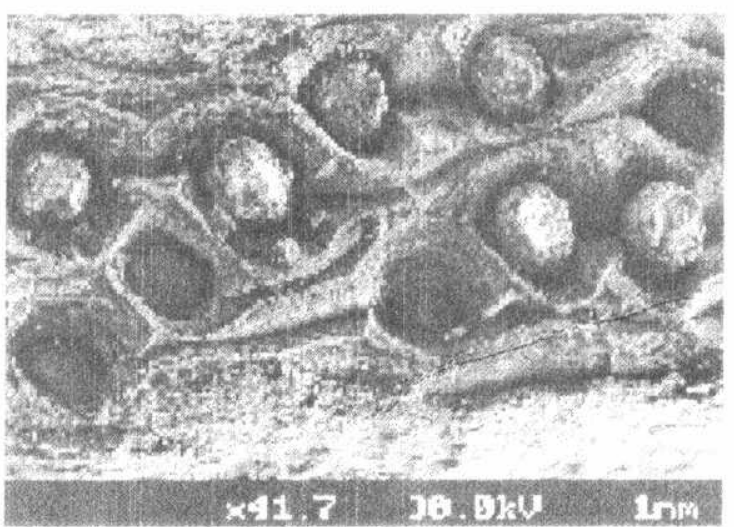

(b)

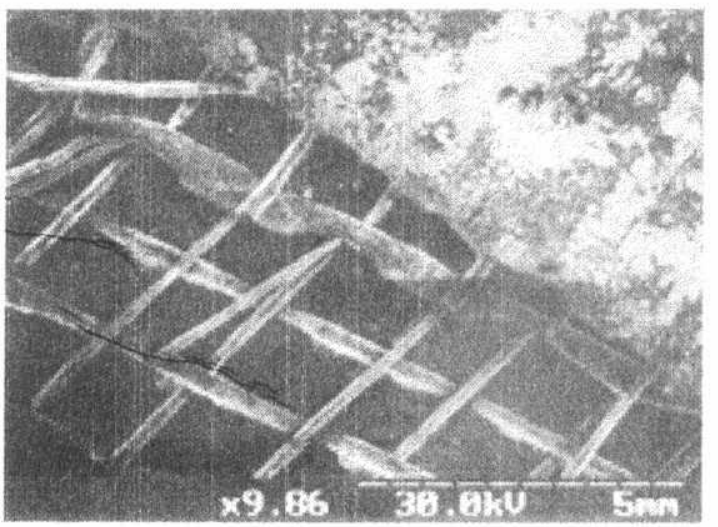

(d)

Figure 5: Ductile-Dimpled Fracture Surface of (a) monolithic Matrix, (b) [0] MMC With steel fibers, (c) [0/90] MMC With steel fibers and Woven fiber composites 